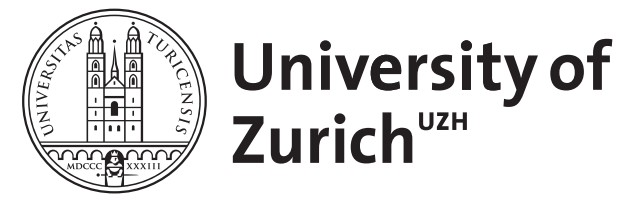

\title{
A tribute to Jean Pictet
}

Hay, Alexandre ; Beer, Henrik ; Lossier, Jean-Georges ; Blishchenko, I P ; Draper, G I A D ; Sultan, Hamed ; Schindler, Dietrich

\begin{abstract}
On 30 June 1979, Mr. Jean Pictet will reach retirement age after forty-two years of service with the ICRC. He joined the ICRC in 1937 and has had a very full career. He is a thinker, a jurist, a writer, a teacher and at the same time a man of action, who took part in all major Red Cross undertakings; he is the inspirer and the mentor of the Red Cross
\end{abstract}

DOI: https://doi.org/10.1017/s0020860400019860

Posted at the Zurich Open Repository and Archive, University of Zurich ZORA URL: https://doi.org/10.5167/uzh-154318

Journal Article

Published Version

Originally published at:

Hay, Alexandre; Beer, Henrik; Lossier, Jean-Georges; Blishchenko, I P; Draper, G I A D; Sultan, Hamed; Schindler, Dietrich (1979). A tribute to Jean Pictet. International Review of the Red Cross, 19(210):115129.

DOI: https://doi.org/10.1017/s0020860400019860 


\section{A TRIBUTE TO JEAN PICTET}

On 30 June 1979, Mr. Jean Pictet will reach retirement age after forty-two years of service with the ICRC.

He joined the ICRC in 1937 and has had a very full career. He is a thinker, a jurist, a writer, a teacher and at the same time a man of action, who took part in all major Red Cross undertakings; he is the inspirer and the mentor of the Red Cross.

Vice-president of the ICRC and member of the ICRC Executive Board, director of the Henry Dunant Institute, chairman of the ICRC Legal Commission, president of the editorial committee of our International Review; author of several well-known books and of many articles, editor and co-author of such important works as the Commentary to the Geneva Conventions, to the Protocols, and of the huge General Report on ICRC activities during the Second World War; an active and often determinant participant in diplomatic conferences, expert groups, study groups and "round tables"-Sometimes responsible for their preparatory works sometimes presiding with undisputed authority and confidence; an interesting lecturer, a professor at the Academy of International Law in the Hague, at Geneva University, at Strasbourg-under the auspices of the Council of Europe and of the University; doctor honoris causa of Leyden and Zurich Universities: Jean Pictet earned the esteem, respect and gratitude of all who met him in person or read his writings and were forcibly attracted by his personality.

In retirement, Jean Pictet will still be very busy, for he will remain a member of the International Committee of the Red Cross and will be associated with various activities of the ICRC. International Review, which owes him so much, extends to him its respectful best wishes. 
Red Cross action would be impossible without profound reflexion which extends and consolidates it and provides it with legal grounds. Since Solferino this certitude has been constantly upheld by such notable figures as Gustave Moynier, Max Huber and now Jean Pictet.

Those who have the privilege of dealing with Jean Pictet realize that he is not only a man of keen intelligence and wide culture, a scholar who is a very fount of learning, but that he is also a man with a heart.

How many times, in moments of crisis, have we heard him flare up at the cruelty which men all over the world inflict on others! This capacity for indignation has not been diminished. Never has he given up the struggle against suffering, for he believes that where there is a will there is always a way.

This contagious faith is expressed in lofty thoughts and penetrating language, sometimes with a caustic touch but tempered with humour at exactly the right place to attenuate the utterance.

So we should not be surprised to see that people for whom the Red Cross is not just one humanitarian organization among others, but a dynamic movement whose forces must be guided and directed and in which none may slumber or lack imagination, turn to him for guidance and counsel.

The Red Cross in general, and the ICRC in particular, owes an immense debt of gratitude to Jean Pictet, whose whole life and thought have served their ideals.

\author{
Alexandre HAY \\ President of the \\ International Committee \\ of the Red Cross
}




\section{A TRIBUTE FROM THE SECRETARY-GENERAL OF THE LEAGUE}

Jean Pictet, in my opinion, personifies the Red Cross. His elevated thinking, sureness of judgement and determination have greatly influenced our whole institution and have contributed decisively to making the Red Cross what it is today.

Our working relationship began just after the Second World War and in 1960 our contacts became almost a daily occurrence. I was thus privileged to see Jean Pictet in action and the importance of his work.

Jean Pictet is a great humanist. He was the architect of the fundamental Red Cross Principles which guide and motivate our movement and give it its true character: spirit of service and self-sacrifice. $\mathrm{He}$ made a major contribution to international humanitarian law through his participation in the work preparatory to the 1949 Geneva Conventions and to the 1977 Protocols, his determinant and active intervention in the Diplomatic Conferences convened to elaborate these treaties, and his renowned Commentary. With modesty Jean Pictet rendered inestimable service to the Red Cross; he is its adviser, known and always heeded throughout the world.

It is a pleasurable privilege for me to express to him the deep-felt gratitude of the League of Red Cross Societies and, through the League, that of all National Societies, wishing him many more years of fruitful activity in which we may count on his moral and intellectual authority, his friendship and his dedication.

Henrik BEER

Secretary-General League of Red Cross Societies 


\section{ONE MAN-THREE CALLINGS}

For almost forty years we worked together in the same institution, for the same ideal, linked by bonds of friendship never impaired by any kind of strain. Such an association entitles me to express my own appreciation of the man-just as he is about to retire-whom I always saw responding splendidly to the challenge in so many different situations. For me, Jean Pictet is a man in whom three callings were combined!

First of all, I think of the mission he pursued at the International Committee of the Red Cross, a mission which is related to the whole history of the Red Cross during and after the Second World War. I see Jean Pictet as a pillar of strength for the ICRC in those difficult days, a man whose physical appearance is certainly not that of a mighty oak but who possesses such moral strength that $I$ have never seen him weaken or despair. His faith in man and in the law protecting man has remained unimpaired. And yet we, and several of our contemporaries, remember for instance that difficult period, immediately after the war, when the ICRC was wondering about the nature of its future tasks and the atomic bomb had sown the seeds of that terrifying uncertainty as to what the future would hold in store for mankind, an uncertainty, too, about the new humanitarian conventions which had to be worked out after the harrowing events of the war.

Jean Pictet took charge of the preparatory work. He nurtured, so to speak, the four Conventions with fervour, until the time when they were ready to be signed in 1949 . He then took over the editorship of the Commentary to the Conventions, as Paul des Gouttes, his one-time mentor, and who had himself been a disciple of Gustave Moynier, had done for the 1929 Conventions. This is a fine example of continuity.

But new measures had to be taken against the rise of violence, and Jean Pictet accordingly harnessed himself to the task, overcoming the doubts felt by some of the leaders and workers in the Red Cross movement and by several governments. It was he who stimulated interest in the work for the development of humanitarian law, an undertaking which a succession of international events increasingly showed to be indispensable and which resulted in the conclusion, in 1977, of the two Protocols.

In the various posts occupied by Jean Pictet from 1937, the year he joined the ICRC as a legal secretary, he bore an increasingly heavy burden of responsibility. After having been one of the most active mem- 
bers on the ICRC staff during the war, he became a director in 1946. In 1966, he was appointed director-general; the following year, he was co-opted a new member of the ICRC and at the same time was made a member of the Executive Board and Chairman of the Legal Commission. In 1971, he became Vice-President of the ICRC. Throughout his career, he rose from one rung to the next with a surety of judgement which is still today one of his qualities and will continue to govern his actions in the new period of liberty which he is soon to enter.

These brief jottings show Jean Pictet as a man of action who does not hesitate, while being rather a thinker by nature, to get things done in a practical manner, to wrestle with the shifting reality of life which demands that swift decisions be taken, with all that they might entail for thousands of people. But, for him, those decisions can only be considered in the light of that supreme and regularizing factor which he calls the "golden rule"- to take into account at all times only the welfare of those in need.

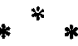

Besides the man of action in Jean Pictet, there is also the writer; his output to date includes six works, but his major contribution is his book on the Red Cross Principles, in which the first impulse was given to establish the values which inspire to relief activities. The Red Cross feeds upon various kinds of philosophical and spiritual nourishment, and each one brings to the Red Cross as much as it receives from it. In The Good Samaritan Max Huber, from whom Jean Pictet derived much of his thought, had already made a significant contribution, from a specifically Christian point of view, to this penetrating quest, in several extremely valuable studies. I too, in my book Solidarity, had analysed the idea of the Red Cross in the perspective of moral philosophy. But what was needed then was to gather the various elements scattered here and there and produce a systematic account of the fundamental notions. Jean Pictet set to work and succeeded in the difficult task of formulating each of those principles in a few short sentences, to which he added a commentary the purpose of which was to define the meaning of the terms employed and the logical relationship between them, and to distinguish some sort of order of significance.

At the heart of the Red Cross were to be found therefore a number of principles which Pictet qualified as "fundamental". They give the institution its specific character, for what they express is no less than its "raison d'être", and they must not be discarded at any cost. A secondary set of principles, called "organic" by Pictet, are related not to the central 
motives of the Red Cross but to its structure and the work of its various parts. Constantly driven by events pressing it daily to act pragmatically, the Red Cross goes back to its fountain-head and understands better that which gives inspiration to its action in a divided world, where ideologies and passions violently oppose each other. This has been so well understood that, since then, the International Red Cross has adopted a formal Declaration of its fundamental principles which, in essence, are the same as those defined by Jean Pictet. And he would not have been able to define them so accurately and so fully had he not been so closely involved in all the most important decisions which had to be taken in, at times, dramatic circumstances.

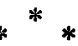

As for the third sphere of activity, his third calling, it is as an innovator than Jean Pictet stands out. Having myself been from the beginning a member of the examining body who questioned his students at their examinations, I know with what knowledge and enthusiastic perception so many of them find their way among the maze of the Conventions of The Hague and of Geneva and of the international instruments on human rights. It is a testimony to Pictet's lively teaching, based on facts and at the forefront of university learning, that the Faculty of Law at Geneva University, where he has the title of associate professor, is one of the first in the world to have introduced international humanitarian law as a regular subject in its curriculum. Besides, the leadership of the Henry Dunant Institute, which he also took over in 1975, forms part of this mission as much as of his calling as a writer: to improve research and teaching at the intellectual level and endeavour to spread the ideal and practice of solidarity nationally and internationally.

It was in 1964 that he began to teach international humanitarian law after he had given a course on this particular subject at the Academy of International Law at The Hague. More recently, he has lectured also at Strasbourg under the auspices of the Council of Europe and of the University. The continuity of this teaching and the influence it exerts have given it an undeniably high standing, and a consequence has been the creation of new chairs in other seats of learning.

For many years, the ICRC has been hoping that such a branch would be introduced in higher educational institutes, for the Geneva Conventions have become part of the heritage of all mankind. Integrated into public international law, they can and must be studied as they deservedly 
should be and in conformity with international undertakings, within the framework of every country's official education policy.

Jean Pictet is certainly today the expert with the widest knowledge of this very special branch of the law of nations, a position which confers on his teaching a particular significance. In the period of openly declared or latent conflicts which we have entered, can there be any more urgent task than the widest possible propagation of knowledge of the legal rules which aim to protect the victims of wars, both national and international?

Confronted as we are at present with the collapse of international morality, the faith of a Jean Pictet in the Geneva Conventions, in their utility and efficacity, and his steadfast confidence in the far-reaching effect of humanitarian service give us comfort and encourage us to march ahead for the defence of human rights.

Jean-Georges LOSSIER

Former Editor-in-chief of

the International Review of the Red Cross

\section{A SCHOLAR}

Jean Pictet is an eminent scholar of international law who has made an outstanding contribution to the theory and practice of international relations. His name is linked to the institution and development of international humanitarian law as a special branch of contemporary international law.

Having held various positions over a long period in the International Committee of the Red Cross, he has not only taken part in practical activities for the provision of humanitarian aid to the victims of armed conflicts: he initiated an original concept of international humanitarian law which has been a model for various schools of thought in many States.

In his writings, as in his practical activities, Jean Pictet has always demonstrated professional and human qualities of the highest order, earning the gratitude and respect of all who have been honoured to work with him.

It may well be said that Jean Pictet's contribution to the common effort to develop and reinforce co-operation among States and nongovernmental institutions for assistance to victims of armed conflicts and for the consolidation of peace will for ever be highly appreciated. The Diplomatic Conference on international humanitarian law at which he worked so hard has turned to a new page in the development of that 
branch of international law, and in co-operation among States on that problem. In this Jean Pictet's merit is outstanding.

I wish Professor Pictet every success in his future work and say to him that we are convinced that the world awaits impatiently for his new writings to enrich the science of international humanitarian law.

\section{Professor I. P. BLISHCHENKO}

Doctor of Legal Science,

Vice-President of the Soviet Lawyers' Association, Secretary to the Association of Democratic Lawyers

\section{A THINKER AND A REALIST}

It has been my unique privilege to have known Jean Pictet for twentythree years during which period $I$ have been able to appreciate his very special personality. Jean Pictet's working life has been, in the full sense of the word, dedicated to the mission of the Red Cross movement and, in particular, to the universal work of the International Committee of the Red Cross. His temperament and outlook were ideally suited to the work of that organization, a work which will always be associated with abiding faith of man in man, with the teaching of humanitarian philosophy, the relief of suffering in war and the protection of the defenceless in the clash of arms.

Descended from a family famed for its services to the City of Geneva for over five hundred years, Jean Pictet embarked upon a career in the service of the International Committee which has been marked throughout by unswerving devotion to the high ideals of Henry Dunant, the founder and "father" of the Red Cross movement. Dunant has had, in our time, no more devoted disciple than Jean Pictet, as can be seen in his many writings over the past three decades. In everything he has written he has expressed, in elegant and lucid French, his philosophical thinking and his practical devotion for the Red Cross ideals, in a world that has been torn apart by unprecedented violence and cruelty in warfare.

Perhaps his most substantial contribution to the literature of the International Humanitarian Law was his general editorship of the four volumes of the Commentary on the four Geneva Conventions of 1949, published by the International Committee over the years 1952 to 1960 . This was a large and authoritative work demanding considerable knowledge. It has a lasting value for jurists and for the mounting numbers of students of Humanitarian Law. 
From 1949 until now Jean Pictet wrote and spoke incessantly on the theme of International Humanitarian Law, a subject which will always be associated with his name. At the same time he was the propounder and promoter of the "Seven Fundamental Principles of the Red Cross" which reflect the philosophy of the Red Cross movement and of the man who did so much to make them articulate. "Humanity, Impartiality, Neutrality, Independence, Voluntary Service, Unity and Universality", who can doubt the value of these principles in the world of today? Jean Pictet has been the constant or standing advocate of these principles, since they were first adopted, at the Twentieth International Red Cross Conference in Vienna in 1965.

After the establishment of the four Geneva Conventions of 1949, now subscribed to by 146 States, the International Committee decided to fill a gap in the humanitarian edifice of protection. This time they sought to secure a modicum of legal protection for the civilian from the effects of modern hostilities. Prominent in this unde taking was Jean Pictet. He presided at the meetings of government experts in Geneva, from 1971 to 1973 , which prepared the draft texts. These became the working documents for the Diplomatic Conference on the Reaffirmation and Development of International Humanitarian Law applicable in Armed Conflicts, convened by the Swiss Federal Government in Geneva and which met for four sessions in the years 1974 to 1977.

This Diplomatic Conference established two Protocols additional to the Geneva Conventions of 1949 which made substantial changes in the law governing the conduct of belligerents in hostilities, so as to cause the minimum loss of life and suffering among the civilian populations. The curtailment of the free range of military operations has been drastic. Throughout this long and arduous work, spread over four years of difficult negotiation and intense legal arguments, Jean Pictet was a patient, calm and assiduous promoter of the humanitarian purpose in war. In the result, these two Protocols were successfully established and came into operation on 7 December, 1978. Jean Pictet and his colleagues of the International Committee have just cause to be proud of this achievement designed to serve the cause of humanity.

Since the conclusion of this Conference he has been responsible for the task of guiding the compilation of the new Commentary on these two Protocols additional to the Geneva Conventions of 1949. It was particularly appropriate that Jean Pictet should have been appointed the second Director of the Dunant Institute in Geneva, consequent upon the tragic death of Pierre Bossier. The Dunant Institute is designed to further the ideals of Dunant and to widen knowledge of the International 
Humanitarian Law throughout the world, as is required by that Law. The world stands in need of such an institute as the knowledge of that Humanitarian Law is sadly lacking. Jean Pictet has helped to make that Institute a living reality and has acted as gubernator of the means of disseminating that Humanitarian Law.

At this moment of Jean Pictet's retirement it is fitting to pay tribute to all that he has done for the international Red Cross movement. Without doubt, he has accomplished great things for that movement, and done so in a manner marked by cool detachment, style, and, not least, a sense of humour that delighted all those who witnessed it. In the press and flurry of Red Cross work, normally performed in crisis conditions, he remained calm and firm.

Those who came to Geneva on Red Cross business will recall his unfailing courtesy and warmth in greeting visitors of all nations. $\mathrm{He}$ speaks as he writes in a French which is a delight to hear and to read. $\mathrm{He}$ acts always as a skilful and patient diplomat in furthering the great cause which is closest to his heart. Last, but not least, he is a very good friend. It is agreeable to reflect that his retirement can in no way impede his gift for amicitia.

Therefore, upon this, the occasion of his retirement, this writer wishes him a happy and full life in his calm retreat in the mountains he loves and in the City of Geneva of which he and the long line of his forbears have been such outstanding citizens. Valedico, Jean Pictet, form all of us who owe you so much and to whom you have been such an inspiration and such a splendid friend.

G.I.A.D. Draper, O.B.E.

Professor in the University

of Sussex

\section{AN ARCHITECT OF INTERNATIONAL HUMANITARIAN LAW}

The first time I encountered Jean Pictet was at the first conference of government experts, convened at Geneva by the ICRC, on the reaffirmation and development of international humanitarian law. The ICRC had asked Mr. Pictet to chair the conference and conduct the deliberations. It was a most felicitous choice as all those present at the opening plenary meeting soon realized. The discussions were conducted by Mr. Pictet with a simple authority and a distinguished equanimity, equalled only by his scrupulous integrity and refined courtesy. The 
function of chairman at a conference is not an easy task. It calls for a combination of qualities: persuasive authority, sound judgment, sense of proportion. The person in the chair must have a liberal, easy and understanding manner. His faculties, as much as his heart, must shine by their generosity, warmth, magnetism and sensibility. By this conduct, he must inspire confidence and impose respect. Jean Pictet amply fulfilled all those conditions.

Towards the end of that opening plenary meeting, after a particularly violent speech by the representative of one of the great Powers, Mr. Pictet, speaking from the chair, made a passionate appeal for reason and peace. He called upon all the experts to maintain the debate at the lofty level which the mission of peace and humanity with which they had been entrusted required of them and to abstain from any discussion of a polemical or political nature. Mr. Pictet's words were uttered with so much sincerity and with such deep feeling that he was loudly acclaimed by everyone present and was listened to with respect at all the subsequent meetings of the conference.

Since that time, I have followed his career with curiosity and interest at first, and very soon after with admiration, an admiration quickly shared by all those who observed him presiding at a meeting. He was considered by all participants as a superb chairman.

Mr. Pictet's many and varied demonstrations in favour of the cause of the reaffirmation and development of international humanitarian law have put him definitely among the top experts in this field. This noble purpose is, so to speak, a reflection of his spirit. His whole soul is in communion with it and it is not difficult to understand how it is that a man whose reasoning is so vigorous and precise was able to act with so much steadfastness and with such a large measure of success. He has been the distinguished orator for a noble cause which he holds dear, and its fearless and brilliant champion.

I owe Mr. Pictet this expression of my admiration for him and his work. It is but a small tribute to one who has served so loyally and for so long the cause of international humanitarian law in armed conflicts. I shall always think of him with feelings of high consideration, great regard and warm affection.

Professor Hamed SULTAN

Member of the Institut d'Egypte, Honorary President of the

Egyptian Society of International

Law. 


\section{THE WRITINGS OF JEAN PICTET}

\section{by $\mathrm{D}$. Schindler}

Jean Pictet's writings are closely related to the practical aspects of his work in the service of the Red Cross. The doctrine he has unfolded in his books has been deeply influenced by practical experience, while what was done in practice was affected by his writings.

Jean Pictet never allows himself to state an abstract theory. Just as the Red Cross came into being through an act and not through reason, so Jean Pictet's writings are not founded upon any preconceived notions: they attempt to deduce a doctrine from everyday events. He once described the Red Cross in terms which can be applied to himself: "Whereas so many institutions, starting from abstract theories, try to adapt beings and things to themselves-like a second Procrustean bedthe Red Cross was, on the contrary, able to model itself on human nature from the outset, and has hammered out its tenets in the rough school of life". ${ }^{1}$

But the notions expounded by Jean Pictet exerted in their turn a profound influence on the decisions which the ICRC and the entire Red Cross were called upon to take. In a period of rapid change, which continually placed the Red Cross in novel and unexpected situations, all those decisions were made in the light of the fundamental principles expounded in Jean Pictet's writings. It is in such fashion that their author has become the authority on moral and legal matters, not only for the ICRC but for the whole Red Cross.

Jean Pictet has published several books and many of his articles have been printed in journals. Mention will be made here only of his principal publications dealing with three closely linked important themes: the Geneva Conventions, the Red Cross principles, and the principles of international humanitarian law.

\footnotetext{
${ }^{1}$ Red Cross Principles (1955), p. 7.
} 
The first of Jean Pictet's important writings about the Geneva Conventions was a paper entitled The Red Cross and the Geneva Conventions, read in 1950 to the Academy of International Law at The Hague, ${ }^{1}$ a year after the four Conventions of 1949 had been adopted. Today it is just as topical as it was in 1950 and may be read with equal interest. It reveals all of Jean Pictet's qualities: restriction to essentials, knowledge of a vast range of subjects, wide practical experience, clarity and simplicity of style, elegance of language. In that lecture, he discussed all the significant points of the Conventions; but, in addition, he identified their significance in the history of the evolution of the law of nations and of the Red Cross.

It is interesting to note that, already at that time, Jean Pictet, following a still unfamiliar line of thought, established a connection between the Geneva Conventions and human rights. One may read what he said of the Geneva Conventions: "They should therefore be linked to the vast movement of international law which, since 1864 when the first Geneva Convention was signed, has attempted to safeguard the fundamental rights of the human person." 2 Later, speaking of the Universal Declaration of Human Rights of 1948, he added: "But this Declaration, as we know, has still to be implemented. It can therefore be said that, here too, in this sphere of paramount importance, it is the law of Geneva which has introduced innovations. Since all the countries of the world have put their signature to the Fourth Geneva Convention, the first charter laying down the obligations in respect of the rights of the human person, let us hope that they will not hesitate at some future date to write into a convention that will be valid at all times and for all persons that which they have accepted with regard to their enemies". ${ }^{3}$

The most voluminous work ever produced on the Geneva Conventions took shape in the Commentary to the Geneva Conventions of 1949, published in four volumes by the ICRC, under the supervision of Jean Pictet. He himself wrote the major part of the two volumes dealing with the First and Second Conventions, but all four volumes were edited by him and written in the same style. The work is not an official publication, for the International Committee was not qualified to lay down an authentic interpretation of the Conventions' provisions. But the commentaries are marked by such a high degree of objectivity and are filled with such

${ }^{1}$ Recueil des cours de l'Académie de Droit international de La Haye, tome 76 (1950, I), pp. 1-119.

2 P. 5.

s P. 111. 
a wealth of information that the reader hardly ever realizes that the opinions expressed do not commit anyone except the different authors.

The book entitled Red Cross Principles, published in $1955^{\circ}$, is a masterpiece of clarity and accuracy. In the preface, Max Huber wrote: "The leaders of the Red Cross movement, and those who wish to write on Red Cross matters, must possess an intelligence which comes near to wisdom; for a very delicate touch is required to perceive the subtleties and limitations in this sphere. But all Red Cross personnel, whatever their work or the posts they occupy, must have hearts and be imbued with the Red Cross spirit. It is the presence of all these qualities of the mind and heart which gives the present work its value and charm". This is the book which established Jean Pictet as the spiritual heir to Max Hubler in the sphere of the Red Cross. The numerous papers and articles which Max Huber published contain many valuable and permanent contributions to Red Cross doctrine, but Jean Pictet was the first to seek to build up a coherent structure of the principles of the Red Cross as the basis of a system.

However, this book is not a law treatise; its purpose is to identify and clarify the principles which impart to the Red Cross its own specific character.

Its author furnishes for all those principles an explanation nourished by the rich experience he had gathered over the years. The book's title and the enumeration of the principles might lead one to think that its contents deal with a highly abstract subject, but in fact the text is extraordinarily alive and stimulating. It was thanks to the existence of Pictet's "Red Cross Principles" that the Twentieth International Red Cross Conference, at Vienna in 1965, adopted the Proclamation of the Fundamental Principles of the Red Cross. A commentary on the 1965 Proclamation by Jean Pictet entitled The Fundamental Principles of the Red Cross was published in the spring of 1979 (Henry Dunant Institute, Geneva). ${ }^{2}$

Next, a book with the title Principles of International Humanitarian Law appeared first in 1966 in several instalments of the International Review of the Red Cross, before being issued as an off-print by the ICRC. It is conceived on the same plan as that adopted for Pictet's earlier book on the Red Cross principles. The author elucidates the principles underlying international humanitarian law and builds up a system on them. The book contains this particularity-its most striking feature-that the notion of international humanitarian law is not restricted to the Geneva

\footnotetext{
${ }^{1}$ ICRC and Librairie E. Droz, Genève.

${ }^{2}$ International Review begins the publication of this work in its present issue.
} 
Conventions, its overall concept includes also human rights and The Hague Conventions on the law of war. It is the first work in which the correlation between the law of war and human rights is examined closely.

Pictet establishes a distinction between the principles common to the law of war and to human rights and those specific to each of those two categories. He calls "common principles" those of inviolability, nondiscrimination and security. The principles of the ratione personae restriction, the ratione loci restriction and the ratione conditionis restriction are specific to the law of The Hague, while the principles of neutrality, normality and protection are specific to the law of Geneva. Under the principles proper to Human Rights he puts the principle of liberty and the principle of social well-being.

The establishment of such a correlation between the law of war and human rights has not been correctly understood by everyone. Some writers considered that Pictet was trying to include human rights in the law of armed conflicts. Others opposed the idea that the law of war and human rights, each of which had developed along wholly different paths, could be correlated. But these critics had viewed Pictet's research from only the dogmatic angle. For him it was irrelevant to say whether the law of war was more important than human rights, or the other way round, nor did he intend to set up a new system of the law of nations; his sole aim was to bring to light the undeniable connection that existed between those branches of law as regards substance. Furthermore, he was not expounding principles of law alone, but also principles of ethics.

Finally, there is the book entitled "Humanitarian Law and the Protection of War Victims", 1 the fruit of a lecture delivered at the Strasbourg International Institute of Human Rights. It is a particularly felicitous reconstitution of some considerations which had been touched upon in Jean Pictet's earlier writings and is a continuation of those considerations.

Among all the things achieved by Jean Pictet for the Red Cross and international humanitarian law, only his writings will remain as the fruit of his personal efforts, while most of his other deeds will be buried in the anonymity of institutions and conferences. But his writings will show them to be the work of a man imbued with the work of the Red Cross, and who has left his personal imprint on the Red Cross institution.

\section{Dietrich SCHINDLER \\ Professor at the Faculty of Law University of Zurich}

\footnotetext{
${ }^{1}$ A. W. Sijthoff, Leyden, and Henry Dunant Institute, Geneva, 1973.
} 